\title{
Topographic mapping of P300 and frontal cognitive function in Parkinson's disease
}

\author{
Mutsumi Iijima*, Mikio Osawa, Makoto Iwata, \\ Akiko Miyazaki and Hideaki Tei \\ Department of Neurology, Neurological Institute, \\ Tokyo Women's Medical University, Tokyo, Japan
}

The purpose of this study was to evaluate the relationship between P300 that is one of the event-related potentials and frontal cognitive functions in Parkinson's disease (PD) without clinically apparent dementia.

Subjects were $20 \mathrm{PD}$ cases 48 to 79 years of age, all of whom were within normal limits on the Mini-Mental State examination, and 55 age-matched healthy adults.

P300 was elicited with an auditory oddball paradigm and recorded at 15 sites on the scalp. Cognitive functioning of the frontal lobe was evaluated using the New Modified Wisconsin Card Sorting Test (WCST) and the Letter Pick-Out Test (LPOT) which reflects selective attention and semantic categorization.

P300 latency was delayed in $30.0 \%$ of subjects and topographic mapping of P300 demonstrated abnormal distribution in $20.0 \%$. Scores of the WCST and the LPOT were abnormal in $15.0 \%, 21.4 \%$, respectively. P300 latency significantly correlated with number of subcategories achieved on the WCST. P300 amplitude correlated with scores on the LPOT. These results suggest that cognitive dysfunction which linked partly to the frontal lobe might begin in PD even without clinically apparent dementia.

Keywords: Parkinson's disease, P300, topographic mapping, frontal lobe function, Wisconsin Card Sorting Test, Letter Pick-Out Test

\section{Introduction}

Parkinson's disease (PD) was originally thought to be a motor disorder without dementia [26], but in the last two decades intellectual deficits have been well corrob-

\footnotetext{
*Corresponding author: Mutsumi Iijima, Department of Neurology, Neurological Institute, Tokyo Women's Medical University, 8-1 Kawada-cho, Shinjuku-ku, Tokyo 162-8666, Japan. Tel.: +8133353 8111; Ext. 39232; Fax: +81 352697324.
}

orated [3]. Recently, some studies have also shown that PD patients without clinically apparent dementia may show abnormalities in frontal lobe function tests [19] suggesting subclinical frontal lobe dysfunction.

P300, one of the event-related potentials (ERPs), is known to reflect cognitive function $[18,33]$, and P300 latency has been shown to be significantly delayed in patients with dementia $[8,25,28]$. Accumulated data have revealed that patients with PD show some abnormality in P300 [9,10,24,29,31,34,37-39].

The purpose of this study was to evaluate the relationship between P300 and frontal cognitive function in PD without clinically apparent dementia.

\section{Methods}

\subsection{Subjects}

Subjects included 20 patients ( 9 males, 11 females) with PD ranging from 48 to 79 years of age (mean $\pm \mathrm{SD} ; 63.1 \pm 10.4$ ), whose duration of illness was 8 months to 10 years (mean $\pm \mathrm{SD} ; 4.9 \pm 2.8$ years). The severity of their motor disability was rated according to Hoehn \& Yahr's stage [11]. One patient was at stage I, 15 at stage II, and 4 at stage III. All patients had normal scores on the Mini-Mental State examination (MMSE) according to the Bleecker's criteria [2]: $\geqslant 29$ points at $40-49$ years, $\geqslant 28$ points at $50-79$ years. All patients were taking anti-parkinsonian medication; 14 patients took levodopa (100-1250 mg/day mean $475.0 \pm 370.4 \mathrm{mg}), 11$ took anticholinergic agents (trihexyphenidyl 1-6 mg/day mean $3.9 \pm 1.4 \mathrm{mg}$ ), 8 took amantadine (100-200 mg/day mean $137.5 \pm$ $35.36 \mathrm{mg}), 5$ took bromocriptin $(7.5-22.5 \mathrm{mg} /$ day mean $10.5 \pm 6.7$ ), and 3 took droxidopa (300-600 mg/day mean $333.3 \pm 251.7 \mathrm{mg}$ ).

Normal controls consisted of 55 healthy adults without dementing illness and with normal MMSE and MRI findings. Their ages ranged from 40 to 79 years (mean $\pm \mathrm{SD} ; 60.5 \pm 10.6$ ) and they included 29 males and 26 females, all of whom were right-handed. In neuropsychological tests, 25 out of 55 normal controls (mean \pm $\mathrm{SD} ; 65.7 \pm 8.2$ years) were examined. 


\subsection{Procedure}

Auditory ERPs were obtained using an auditory oddball paradigm. The target tone was $2000 \mathrm{~Hz}$, and 20\% of all stimuli, and the frequent tone, which was the nontarget tone, was $1000 \mathrm{~Hz}$ and $80 \%$. The intensity of stimulation was $70 \mathrm{~dB}$ at normal hearing level, and the duration was $50 \mathrm{~ms}$. The inter-stimulus interval was 1.7 seconds. One hundred artifact-free stimuli were averaged for a block. Two blocks were performed to confirm reproducibility and averaged off-line for each subject. The subjects were tested while in a comfortable chair and instructed to count silently the number the target tones, and to answer their count after each block. Counting accuracy was better than $95 \%$ for all subjects. Fifteen sites (F3, FZ, F4, C3, CZ, C4, P3, PZ, P4, T3, $\mathrm{T} 4, \mathrm{~T} 5, \mathrm{~T} 6, \mathrm{O} 1, \mathrm{O} 2)$ were recorded according to the international 10-20 system. The reference was linked earlobes and the band pass filter 0.5 to $30 \mathrm{~Hz}$. Electrode impedance was maintained below $5 \mathrm{~K} \Omega$. Analysis time was from $70 \mathrm{~ms}$ before stimulation to $630 \mathrm{~ms}$ after stimulation. The rejection level was $\pm 96 \mu \mathrm{V}$ on electrooculogram and electroencephalogram. We evaluated P300 component in ERPs to target stimuli, using the time windows defined as the most positive peak occurring within the 250-500 ms post-stimulus.

A topographical analysis was based on the amplitude values obtained from the 15 electrodes at the latency of P300 at Cz. The P300 topographical map (TM) was generated from the inter-electrode amplitude values that were obtained by means of a standard splineinterpolation algorithm. After the individual maps were developed for the normal subjects, age-group maps were generated using grand averages. To evaluated whether the topography of P300 in a patient was different from that of age-matched normal controls, significant probability maps (SPM) was computed based on Z-score differences of patient data from the controls [5]. Abnormal P300 TM was defined as -2SD or less on the Z-score map.

In order to evaluate the cognitive functions of the frontal lobe, we employed the New Modified Wisconsin Card Sorting Test (WCST) [16] and the Letter PickOut Test (LPOT) [13]. The subscores derived from the WCST included categories achieved (CA), perseverative errors of Milner (PEM) [22], perseverative errors of Nelson (PEN) [23], and difficulty in maintaining set (DMS). In the LPOT, subjects were instructed to mark the Japanese syllabary characters (five vowels; a, i, u, e, o) with a pen from a Japanese fairy tale in two minutes. Immediately after the test, the subject was asked about
Table 1

Comparison of P300 between controls and Parkinson's disease patients

\begin{tabular}{lcc}
\hline & Controls & PD \\
\hline P300 latency $(\mathrm{msec})$ & & \\
Fz & $334.2 \pm 38.9$ & $359.7 \pm 57.6^{*}$ \\
Cz & $333.4 \pm 40.3$ & $367.9 \pm 69.3^{* *}$ \\
Pz & $333.0 \pm 40.2$ & $365.7 \pm 65.1^{*}$ \\
P300 amplitude $(\mu \mathrm{V})$ & & \\
Fz & $7.14 \pm 3.21$ & $6.44 \pm 2.46$ \\
Cz & $8.27 \pm 3.48$ & $7.66 \pm 2.36$ \\
Pz & $8.96 \pm 3.48$ & $8.35 \pm 2.26$ \\
\hline
\end{tabular}

mean $\pm \mathrm{SD},{ }^{*} P<0.05,{ }^{* *} P<0.01$.

the story. The collect answers are scored and the full mark is 61. According to the Kaneko's definition [14], the LPOT was defined as abnormal when the score was below $15,10,9$, respectively, in patients in their 50's, 60's, and 70's.

Statistical comparisons of P300 data between the PD group and the normal control group were evaluated by Student's t-test test. Drug effects on the P300 data were evaluated by One-way analysis of variance (ANOVA). Spearman's Rank correlation was used to correlate the neuropsychological test scores with the P300 data. Wilcoxon- Mann-Whitney test was used to evaluate differences of the P300 data and the neuropsychological test scores between two groups which consisted of patients with normal P300 TM or with abnormal P300 TM.

\section{Results}

\subsection{P300 latency and amplitude}

P300 latency was delayed at Fz in 25\% of PD patients and at, $\mathrm{Cz}$ and at $\mathrm{Pz}$ in 30\%. P300 latency of PD patients was significantly delayed at $\mathrm{Fz}, \mathrm{Cz}$, and $\mathrm{Pz}$ compared to the controls (Table 1). P300 amplitude of PD patients was not significantly different at any recording site.

\section{2. $P 300 T M$}

Sixteen PD patients showed normal distribution of P300. Abnormal P300 TM was disclosed in four patients including three patients with frontal shift (Figs 1 and 2) and one with right centroparietal shift. One patient whose TM showed frontal shift had delayed P300 latency. However, P300 latencies in the other three patients were within normal limits. 


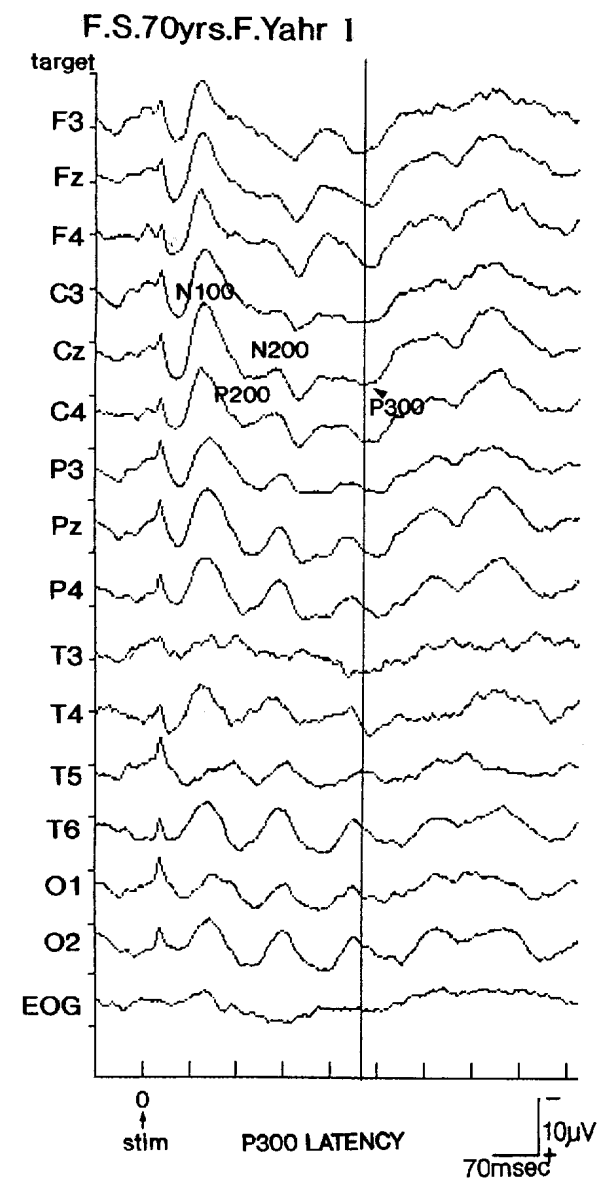

Fig. 1. ERP recording in a 70-year-old female with Parkinson's disease. The peak latency of P300 is within normal limits.

\subsection{Neuropsychological correlates of $P 300$}

Table 2 shows scores of subcategories on the WCST in the two groups. There was not significant difference between two groups, but abnormality in CA, PEM and PEN were seen in $15 \%$ of the cases and DMS was abnormal in $5 \%$ according to the data defined as - 2SD or less on the mean in the normal controls.

The scores of the LPOT were from 3 point to 30 points (mean \pm SD $16.3 \pm 7.1$ points), and abnormal in three patients $(21.4 \%)$ out of 14 patients.

$\mathrm{P} 300$ latency at $\mathrm{Pz}$ in the patients was significantly $(p<0.05, \rho=0.53)$ correlated with DMS scores, and that at $\mathrm{Fz}$ was inversely correlated $(p<0.05$, $\rho=-0.60)$ with scores in the LPOT. P300 amplitudes showed no significant correlation with any of the subscores derived from the WCST, but a significant $(p<0.05, \rho=-0.71)$ inverse correlation was found between P300 amplitude at Fz and scores in the LPOT. In the patients with abnormal scores of the WCST or the LPOT, P300 TMs showed normal distribution. There was no statistically significant relationship between P300 TM and any score of the WCST subcategory or the LPOT.

\subsection{Effects of anti-parkinsonian drugs}

Latencies and amplitudes of P300, scores of the WCST and the LPOT test were not significantly correlated with any anti-parkinsonian drugs by ANOVA.

\section{Discussion}

This study showed that P300 latency was significantly delayed in non-demented PD patients. Although there have been many reports of delayed P300 latency in demented PD [9,10,24,31,34,37,39], delayed P300 latency in non-demented PD has been reported in only a few studies $[1,29,35]$. Several authors showed normal P300 latency in non-demented PD [9, 15]. Tsuchiya [38] reported that prolonged P300 latency to novel stimuli but not delayed P300 latency to target stimuli in non-demented PD. These differences of P300 latency may be due to task-specific, stimulus modality and response requirements.

Considering the effects of anti-parkinsonian drugs on ERPs, Prasher and Findley [29] showed that in non-demented PD, P300 latency before dopaminergic treatment was not significantly different from that of their control subjects, but after treatment P300 latency was significantly prolonged. However, some other authors have described the opposite results with normal P300 latencies in PD patients medicated with anti-parkinsonian drugs [6,15,32,34,37]. In addition, Tachibana [35] showed delayed P300 latency in untreated PD patients. There were not significant correlations between anti-parkinsonian drugs and latencies and amplitudes of P300 in this study. P300 latency is related to the time of cognitive processing of registered information [4]. Our findings suggest that cognitive function as indicated by P300 latency may already be abnormal in PD patients even without clinically apparent dementia.

Abnormal P300 TM was disclosed in four patients, including three with frontal shift. Such frontal shift might be due to accelerated aging [17], which is reported to be caused by reduction in amplitude of P3a (which is elicited by novel stimuli at the frontal site), at $\mathrm{Cz}$ [27] or by decreased frontal negative wave [30]. 


\section{P300 TOPOGRAPHIC MAPPING}

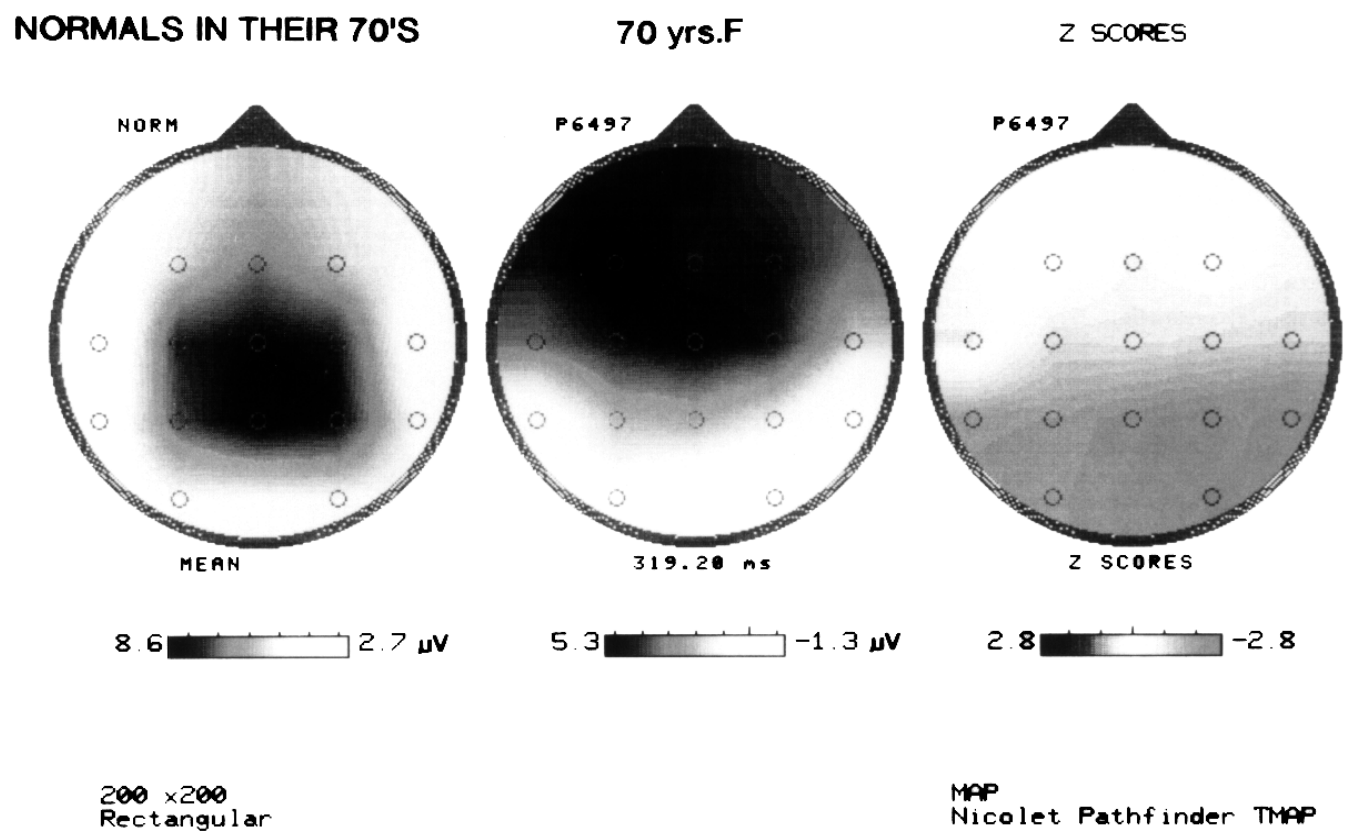

Fig. 2. P300 topographic mapping in a Parkinson 's disease patient. The topographic mapping of 70-year-old female with Parkinson's disease. The peak latency of P300 is within normal limits. Left map: The grand average in normal controls in their 70's and topographic distribution of P300 is dominant at central to parietal derivations. Middle map: Topographic distribution in the patient is frontally shifted. Right map: The Z score map shows significant decrease at the parietal region.

Table 2

Results of Modified Wisconsin Card Sorting Test

\begin{tabular}{|c|c|c|c|}
\hline \multicolumn{2}{|c|}{ Controls } & \multicolumn{2}{|c|}{ Parkinson' disease } \\
\hline & Scores $^{\mathrm{a}}$ & Scores & cases of abnormality $(\%)$ \\
\hline $\mathrm{CA}$ & $2.7 \pm 1.8$ & $2.7 \pm 2.0$ & $3(15.0)$ \\
\hline PEM & $13.0 \pm 9.7$ & $15.8 \pm 12.4$ & $3(15.0)$ \\
\hline PEN & $7.5 \pm 5.7$ & $8.1 \pm 8.0$ & $3(15.0)$ \\
\hline DMS & $1.4 \pm 1.1$ & $1.5 \pm 1.6$ & $1(5.0)$ \\
\hline $\begin{array}{l}{ }^{a} \text { Data } \\
\text { CA: ca } \\
\text { PEM: } \\
\text { PEN: } \\
\text { DMS: } \\
\text { abnorn }\end{array}$ & $\begin{array}{l}\text { re shown as } n \\
\text { egories achie } \\
\text { erseverative e } \\
\text { rseverative e } \\
\text { ifficulty in } m\end{array}$ & $\begin{array}{l} \pm \text { SD. } \\
\text { of Milner. } \\
\text { of Nelson. } \\
\text { ining set. } \\
\text { w the scores }\end{array}$ & . \\
\hline
\end{tabular}

Some pathologic changes of cognitive function in PD may be involved in the frontal shift of P300, like other neurological disorders with dementia [20]. In three of four patients with abnormal distribution of P300, their P300 latencies were within normal limits. Previous study reported same discrepancy in multi-infarct dementia [25]. This discrepancy was thought to cause of differences of reflection to cognitive functions between P300 latency and P300 TM. P300 latency is the index of the time of controlled information processing [4] whereas P300 TM and amplitude are the indices of selective attention to stimulation and allocation of information resources [28].

The WCST was found to be abnormal in $15 \%$ of 
PD patients without clinically apparent dementia. This finding is in agreement with previous reports [19]. CA, PEM and PEN are indices of the changing of mental sets, whereas DMS is an index of the maintaining of mental sets [22,23]. These functions to modify mental sets are thought to originate in the frontal lobes [23]. Recently the WCST is thought to reflect the function of not only several frontal regions, in particular, the dorsolateral prefrontal cortex, but also the inferior parietal lobe, the visual association cortex, the inferior temporal lobe and portions of the cerebellum [21]. The LPOT is used as one of the frontal lobe tests in Japan, based on studies in the patients with frontal lobe, especially prefrontal lobe, injury $[13,14]$. It requires discrimination, comparison, and decision, and is based on the combined functions of attention, memory, visuospatial cognition, and movements of upper limb and eyes [13]. The scores of the LPOT showed significant low scores in PD group [7].

Impaired frontal cognitive functions in $\mathrm{PD}$ are thought to be caused by the degeneration of dopaminergic tracts projecting to the frontal cortex from the basal ganglia, which include the complex loop connecting the caudate nucleus with the frontal cortex via the thalamus [36] and the mesocorticolimbic pathway [12]. The cholinergic subcortico-frontal pathway as a nondopaminergic pathway was also involved with cognitive impairment in PD. The WCST and the LPOT should therefore be useful for detecting neuropsychological disturbances in clinically non-demented PD.

$\mathrm{P} 300$ latency at $\mathrm{Pz}$ in our patients was significantly correlated with DMS scores which reflect the maintaining of mental sets. This correlation may indicate that the ability to maintain mental sets influences P300 latency. Yamada et al. [39] showed that P300 latency was significantly correlated with CA, DMS and PEM scores, reflecting the ability to shift concepts. P300 amplitude at Fz was correlated with scores of the LPOT. This significant correlation may therefore indicate that PD patients with lower scores on the LPOT need more allocation of information resources and more selective attention.

No significant relationship was found between P300 TM and any of the subscore derived from the WCST presumably because the neural processes underlying performance on the WCST and the neural processes underlying P300 are distinct. Performance on the WCST is thought to reflect the function frontal regions, in particular, the dorsolateral prefrontal cortex, and another cerebral cortices and portions of the cerebellum [21], while P300 represents the combination waves gener- ated from various cortical sites including the frontal and subcortical regions. The frontal lobe, however, as indicated by the relationship between P300 measures and performance on some subcategories of frontal lobe tests, may be involved in some part of the generation of P300 in PD patients without dementia.

\section{References}

[1] G. Amabile, F. Fattaposa and F. Pierelli, Evoked potentials in Parkinson's disease: Sensory and cognitive aspects, A review. J. Psychophysiol 4 (1990), 122-155.

[2] M.L. Bleecker, K. Bolla-Wilson, C. Kawas and J. Agnew, Agespecific norms for the Mini-Mental State Exam, Neurology 38 (1988), 1565-1568.

[3] R.G. Brown and C.D. Marsden, Cognitive function in Parkinson's disease: from description to theory, Trends in Neuroscience 13 (1990), 21-29.

[4] E. Donchin, Surprise! -_Surprise? Psychophysiol 18 (1981), 493-513.

[5] F.H. Duffy, P.H. Bartels and J.L. Burchfiel, Significance probability mapping; an aid in the topographic analysis of brain electrical activity, Electroencephalogr Clin Neurophysiol $\mathbf{5 1}$ (1981), 455-462.

[6] K.P. Ebmeier, D.D. Potter, R.H.B. Cochrane, J.R. Crawford, L. Stewart, S.A. Calder, J.A. Besson and E.A. Salzen, Eventrelated potentials, reaction time and cognitive performance in idiopathic Parkinson's disease, Biol Psychol 33 (1992), 73-89.

[7] T. Fukui, Y. Sato, H. Ichikawa, T. Takeuchi, K. Sugita and H. Tsukagoshi, Evaluation of influential factors of cognitive impairments in idiopathic Parkinson's disease, Eur Neurol 35 (1995), 86-92.

[8] D.S. Goodin, K.C. Squires and A. Starr, Long latency eventrelated components of the auditory evoked potential in dementia, Brain 101 (1978), 635-648.

[9] D.S. Goodin and M.J. Aminoff, Electrophysiological differences between demented and non-demented patients with Parkinson's disease, Ann Neurol 21 (1987), 90-94.

[10] E.C. Hansch, K. Syndulko, S.N. Cohen, Z.I. Goldberg, A.R. Potvin and W.W. Tourtellotte, Cognition in Parkinson disease: an event-related potential perspective, Ann Neurol 11 (1982), 599-607.

[11] M.M. Hoehn and M.D. Yahr, Parkinsonism: onset, progression and mortality, Neurology 17 (1967), 427-442.

[12] F. Javoy-Agid and Y. Agid, Is the mesocorticol dopaminergic system involved in Parkinson's disease? Neurology 30 (1980), 1326-1330.

[13] M. Kaneko, Dementia and frontal lobe function, Higher Brain Function 10 (1990), 127-131, (Japanese).

[14] M. Kaneko, Screening test for the diagnosis of early senile dementia, J Senile Dementia 5 (1991), 41-48, (Japanese).

[15] F. Karayanidis, S. Andrews, P.B. Ward and R.T. Michie, ERP indices of auditory selective attention in aging and Parkinson's disease, Psychophysiology 32 (1995), 335-350.

[16] H. Kashima and M. Kato, Tests for frontal function -pattern of frontal dysfunction and its assessment, Adv. Neurol. Sci. 37 (1993), 93-110, (Japanese).

[17] A. Kok and E.J. Zeef, Arousal and effort: A review and theoretical synthesis of studies of age-related changes in eventrelated potentials, in: Event-Related Brain Reseach (EEG 
Suppl. 42), C.H.M. Brunia, G. Mulder and M.N. Verbaten, eds., Elsevier, Amsterdam, 1991, pp. 324-341.

[18] M. Kutas, G. McCarthy and E. Donchin, Augmenting mental chronometry: The P300 as a measure of stimulus evaluation time, Science 197 (1977), 792-795.

[19] A.J. Lees and E. Smith, Cognitive deficits in the early stages of Parkinson's disease, Brain 106 (1983), 257-270.

[20] K. Maurer, T. Dierks, R. Ihl and G. Laux, Mapping of evoked potentials in normals and patients with psychiatric diseases, in: Topographic Brain Mapping of EEG and Evoked Potentials, K. Maurer, ed., Springer-Verlag, Berlin, Heidelberg, 1989, pp. $458-481$.

[21] A.R. Mayes and I. Daum, How specific are the memory and other cognitive deficits caused by frontal lobe lesions? in: Methodology of Frontal and Executive Function, P. Rabbit, Psychology Press Publishers, UK, 1997, pp. 155-175.

[22] B. Milner, Effects of different brain lesions on card sorting. The role of the frontal lobes, Arch Neurol 9 (1963), 90-100.

[23] H.E. Nelson, A modified card sorting test sensitive to frontal lobe defects, Cortex 12 (1976), 313-324.

[24] B.F. O'Donnell, N.K. Squires, M.J. Martz, J.R. Chen and A.J. Phay, Evoked potential changes and neuropsychological performance in Parkinson's disease, Biol Psychol 24 (1987), 23-37.

[25] M. Osawa, P300 and neuropsychological function in normal aging and dementia, in: Perspectives of Event-Related Potentials Research (EEG Suppl. 44), G. Karmos, M. Molnar and V. Csepe et al., Elsevier, Amsterdam, 1994, pp. 369-376.

[26] J. Parkinson, An essay on the shaking palsy, London, Sherwood, Neely and Jones, 1817.

[27] T.W. Picton, D.T. Stuss, S.C. Champagne and R.F. Nelson, The effects of age on human event-related potentials, Psychophysiol 21 (1984), 312-325.

[28] J. Polich, P300 in clinical applications: meaning, method, and measurement, Am J EEG Technol 31 (1991), 201-231.

[29] D. Prasher and L. Findley, Dopaminergic induced changes in cognitive and motor processing in Parkinson's disease: an electro-physiological investigation, $J$ Neurol Neurosurg Psychiatry 54 (1991), 603-609.

[30] D.B. Smith, H.J. Michalewski, G.A. Brent and L.W. Thompson, Auditory averaged evoked potentials and aging: factors of stimulus, task and topography, Biol Psychol 11 (1980), $135-151$.

[31] S.E. Starkstein, M. Esteguy, M.L. Berthier, H. Garcia and R. Leiguarda, Evoked potentials, reaction time and cognitive performance in on and off phases of Parkinson's disease, $J$ Neurol Neurosurg Psychiatry 52 (1989), 338-340.

[32] P. Stanzione, F. Fattapposta, P. Giunti, C. D' Alessio, M. Tagliati, C. Affricano and G. Amabile, P300 variations in parkinsonian patients before and during dopaminergic monotheraphy: A suggested dopamine component in P300, Electroencephalogr Clin Neurophysiol 80 (1991), 446-453.

[33] S. Sutton, M.L. Braren and J. Zubin, Evoked- potential correlates of stimulus uncertainty, Science 150 (1965), 1187-1188

[34] H. Tachibana, K. Toda and M. Sugita, Actively and passively evoked P3 latency of event-related potentials in Parkinson's disease, J Neurol Sci 111 (1992), 134-142.

[35] H. Tachibana, K. Aragane, Y. Miyata and M. Sugita, Electrophysiological analysis of cognitive slowing in Parkinson's disease, J Neurol Sci 149 (1997), 47-56.

[36] A.E. Taylor, J.A. Saint-Cyr and A.E. Lang, Frontal lobe dysfunction in Parkinson's disease. The cortical focus of neurostriatal outfllow, Brain 109 (1986), 845-883.

[37] K. Toda, H. Tachibana, M. Sugita and K. Konishi, P300 and reaction time in Parkinson's disease, J Geriatr Psychiatry Neurol 6 (1993), 131-136.

[38] H. Tsuchiya, S. Yamaguchi and S. Kobayashi, Impaired novelty detection and frontal lobe dysfunction in Parkinson' s disease, Neuropsychologia 38 (2000), 645-654.

[39] T. Yamada, K. Katayama and K. Hirayama, Neuropsychogical disturbance in Parkinsn's disease - by the analysis of New Modified Wisconcin Card Sorting Test and P300 component evoked by auditory stimuli-, Brain and Nerve 39 (1987), 643 647, (Japanese). 


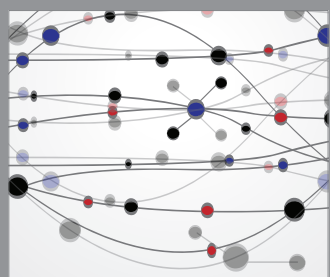

The Scientific World Journal
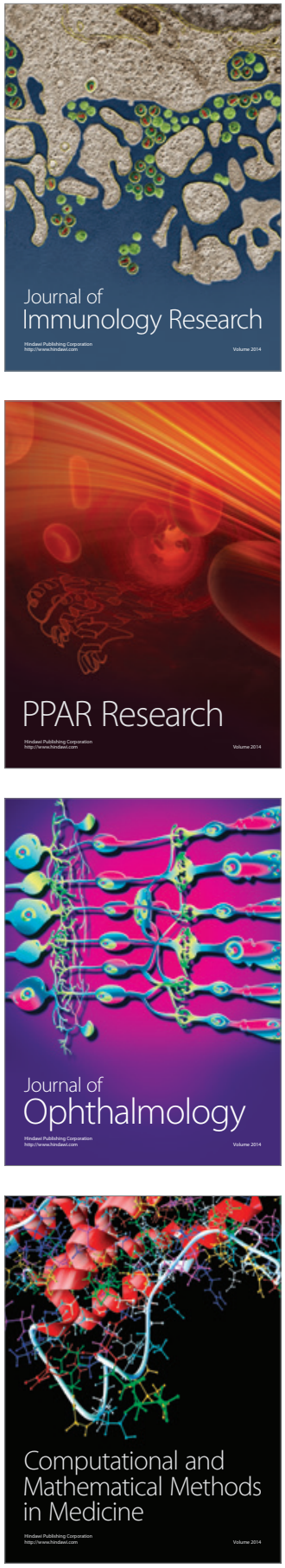

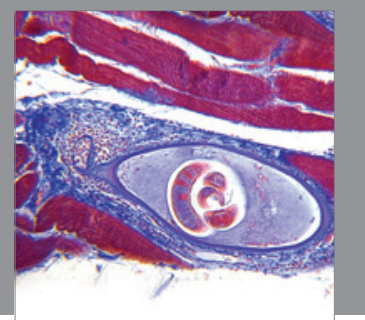

Gastroenterology

Research and Practice
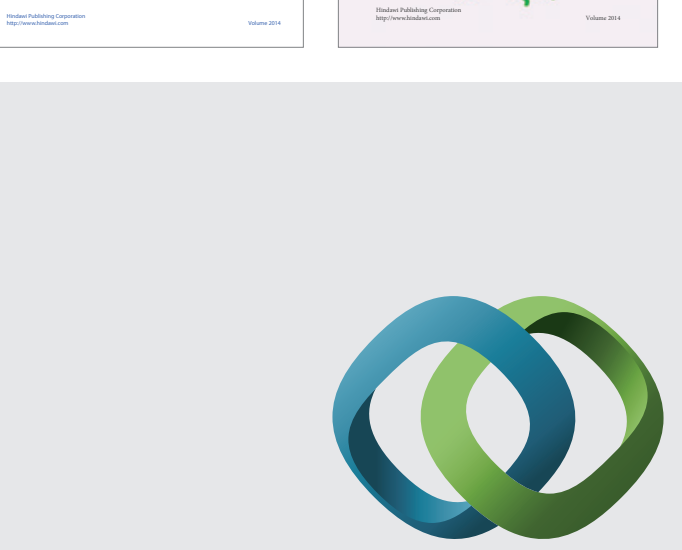

\section{Hindawi}

Submit your manuscripts at

http://www.hindawi.com
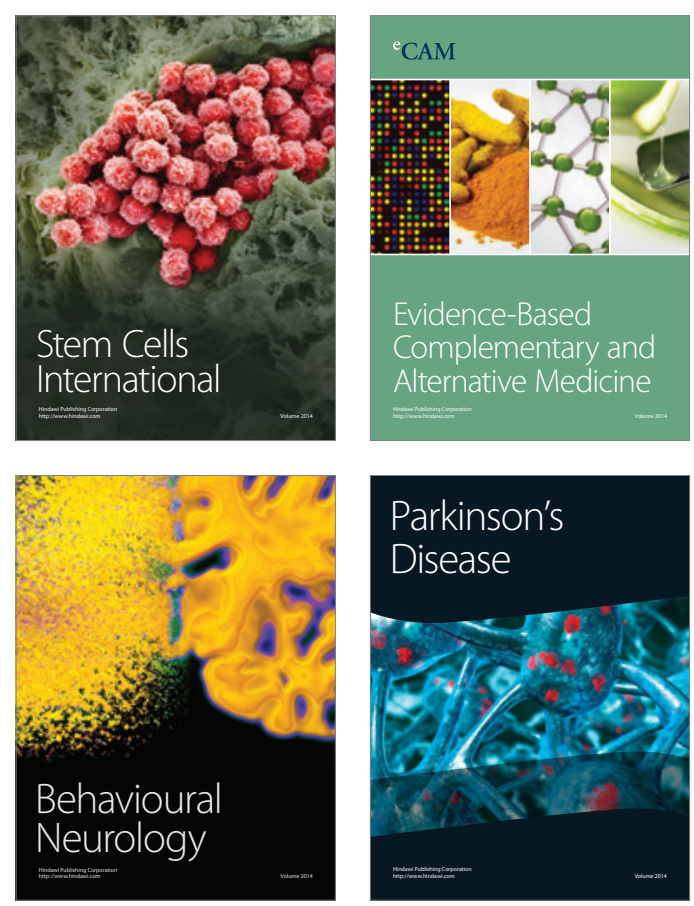

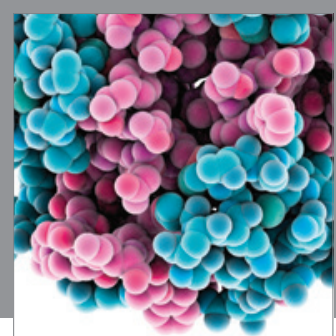

Journal of
Diabetes Research

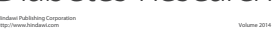

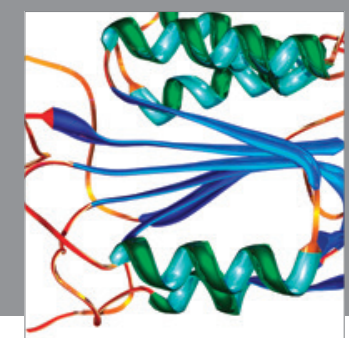

Disease Markers
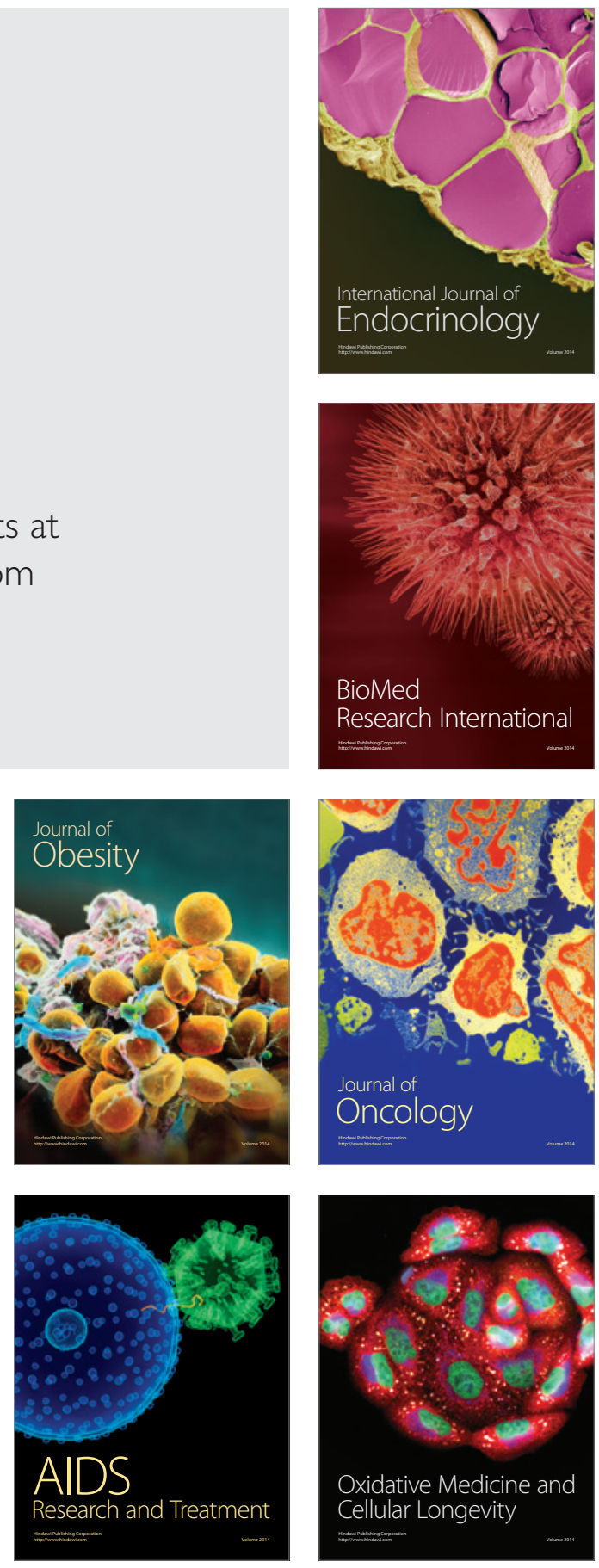